\title{
Research on Online Education in the Midst of the COVID-19 Pandemic
}

\author{
Huang Yabin \\ Humanities and Social Sciences College, Heilongjiang Bayi Agricultural University, Daqing, Heilongjiang, 163319, \\ China \\ Email: dqhuanghyb@163.com
}

\begin{abstract}
Face-to-face education is affected by the COVID-19 pandemic, so most face-to-face education and training institutions in China have suspended their courses. In order to strengthen the prevention and control of the new pneumonia and reduce the impact of the pandemic on the normal teaching, many teachers make full use of the network platform, WeChat, QQ and other ways, actively carry out online teaching, independent learning and online counseling, and other teaching activities. How to minimize the impact of the pandemic on students' learning is an very important question that every educator thinks about carefully. Meanwhile, online education has an unexpected opportunity. This paper analyzes the advantages, limitations, teaching strategies and development of online education in order to break through the limitations of online education to enhance the value of online courses, and provide guidance for optimizing teaching content and improve teaching effect.
\end{abstract}

Keywords: the COVID-19 pandemic, online learning, online education

\section{Theoretical Basis of Online Education}

\subsection{Theory of Independent Study by Charles Wedemeyer \& Michael G Moore}

Both Charles Wedemeyer and Michael G Moore introduced theories of independent study involving the degree of independence of the student and the distance between the teacher and the learner. Wedemeyer set forth a system of 10 characteristics emphasizing learner independence and adoption of technology as a way to implement independence. He pointed out that the ubiquitous teaching technology will promote the development of anytime and anywhere learning. Michael Moore classified distance education programs as 'autonomous' (learner-determined) or 'Non-autonomous' (teacher-determined). He theorized that Independent Study is a classification method for distance education programs. His theory examines the amount of learner autonomy and the distance between teacher and learner.

\subsection{Guided Didactic Conversation by Holmberg}

Distance education includes both real and mediated communication processes, and the purpose of the two-way communication is to motivate and facilitate students in learning and to provide feedback (Holmberg, 1977; 1981). Education is based on communication between teacher and student, and on peer group interaction, and as a method of guided didactic conversation, distance education aims at learning and the conversation facilitates learning (Holmberg, 1983; 1985). Holmberg emphasized that students are not subordinate in the teaching process, the relationship between students and teachers and whether the learning content has personal significance will affect the learning effect.

\section{Advantages of Online Education}

Online education has numerous excellent teachers and large amounts of leaning resources. Online learning has become an important way for people to learn. It is considered as the most helpful approach to seek knowledge in the context of the New Coronavirus pandemic. In the midst of the prevention and control of the pandemic, learners needn't go to the school for learning. Learners can get to their courses 24 hours in a day. Online education provides learners with learning support, ensures timely access to online 
high-quality course resources, strengthens the quality requirements of online learning process and multiple assessment. In addition, educators make every effort to protect learners from the pandemic through online teaching. Its advantages are reflected in the following aspects:

Through the online education platform, learners and teachers can carry out teaching activities even if they are thousands of miles away. Online education is the most convenient way to learn and improve new skills. In addition, through online education, it can realize the optimization of resource utilization, independent learning, interactive learning, personalized teaching, automation of teaching management. In particular, users in remote areas have a higher thirst for high-quality online learning resources than those in developed areas. In third and fourth cities, teacher resources, especially high-quality teacher resources, are very scarce. Online education can help these people break through geographical and resource constraints and spread high-quality resources from developed cities to third and fourth cities through the online education platform.

With the advantages of online education being noticed by more and more people, the learners who choose to learn through online education are growing. Online education not only breaks down the barriers of time and space, but also starts to impress users with lower cost and diversified teaching and evaluation modes, so as to meet the personalized needs of users. Online education promotes the change and reform of traditional teaching mode. Learners have a more autonomous and personalized learning experience of choosing the learning environment according to their own knowledge and ability. Teachers reconstruct the course structure and improve teaching methods. The technology of online education makes teaching management more effective, and the technology also blurs the geographical boundary of schools. The structure of the teaching staff of each school has been changed and the composition of the teaching staff has the diversified characteristics of "the main lecturer + the auxiliary staff + the technical staff".

In addition, question bank and homework answering (tools): its functions are accurate analysis, user portrait and timely answering. Online question bank is the intelligent terminal software. On the basis of learners' searching data and learners' feedback data, the online question bank accurately analyzes learners' knowledge points in order to improve their learning efficiency. The online question bank will include a number of learning tools, including photo search, composition search, voice search and other ways to get solutions to difficult problems and test points.

\section{$3 \quad$ Limitations of Online Education}

First, the current online education industry reached a certain scale, but online education in China is still in its infancy stage. Online education institutions remain only rooted in foreign language training before examination training, and technical ability training, in other words, online English courses are more and seldom dabbled in other fields, which result in convergence phenomenon of education products is serious.

Second, innovation is not enough. For example, in the traditional learning process, teachers' face-to-face encouragement plays an important role in most students' learning effect, however, as far as distance course is concerned, it is difficult to urge students to keep studying, in other words, students will feel tired and bored after studying in front of a computer screen for a long time, which can give rise to the decrease in their learning efficiency. Therefore, the innovation of online education involves various aspects. How to innovate, which aspect to innovate, and how to cultivate innovative talents in the online education industry are all challenges faced by online education in China [2].

Third, because teachers and students are not face-to-face teaching and they cannot see their body language each other, it is difficult to effectively mobilize students' learning enthusiasm and creativity. In addition, the interaction between teachers and students is insufficient though online teaching, in other words, teachers are unable to pay attention to the learning effect of every student in time.

\section{Online Teaching Strategies}

\subsection{Keeping an Eye on the Needs of Online Learning Users}

In live courses of online education, one of the best functions is that students can replay the live video according to their own weaknesses. The live online courses adopt the high-level double-qualified teachers model to reshape online learning and teaching method. The dual-teacher teaching model of 'live teaching 
+ after-class tutoring' is adopted, that is, one instructor conducts live teaching and the other instructor coordinates with the learning tracking of learners. In live online class and online after-class tutoring, the teachers keep paying attention to the needs of online learning users, so as to continuously update teaching resources and better improve the teaching effect.

\subsection{Cooperation and Communication between Family and School}

The family-school interactive platform is usually a website or APP product derived from the application of educational informatization, which focuses on the browsing of educational resources and the tracking of students' online school status. APP aimed at after-class and 'flip' class online education, closely around the live class teaching. Through the computer, tablet and mobile client, online education services provide teaching and learning, practice, measurement, auxiliary, communication and integration services, students' autonomous learning, the service of after-school omni-directional tutoring for parents. In addition, teachers can send feedback of students' performance in the online class to parents instantly through the APP. The data of App can also assist teachers and parents to evaluate and help students' learning.

\subsection{Combination of Training and Employment}

The main purpose for users to use the online education platform is to learn. If the online education platform can provide learners with professional and practical knowledge for free, and provide personalized guidance resources for their career in the future, there is no reason for learners to refuse such a convenient way to learn. Therefore, the enterprise' job demand and the feasible strategies of enterprise development will be introduced into the online education platform, and targeting talent training for enterprise will be realized. This new training and employment model can effectively improve the competitiveness of online education platform.

\section{Development of Online Education in the Future}

\subsection{The Best Hope of Online Education Industry in the Future}

The essence of education is service, and live service is closer to face-to-face training experience, which will be the best hope of online education industry in the future. The educational service industry particularly pays attention to teaching effect, the service and the teaching research in order that online education enterprises become bigger and stronger. Teaching and research is still the core essence of the development of all online education enterprises. High-quality resources and excellent teachers are the foundation of the educational service industry and the key to the recognition of teaching quality. The deep integration of education industry and Internet technology will help education change from closed to open and redeploy the resources of the education industry. Integration of online and offline education become an integral part of the global education system.

\subsection{Precision Teaching in the Context of AI Big Data}

In the future, students will be accurately evaluated based on big data, and personalized services will be provided to students according to the standard of "effect and efficiency", which is expected to truly teach students according to their aptitude. Artificial intelligence, big data and other technologies continue to promote the development of "education + Internet". Information technology research and development of related technologies will continue to help the innovative development of the education industry and continuously improve learners' experience. The integration of technology and education will continue to deepen. It is not difficult to find that technology is reconstructing learning experience, such as enhancing visualization through the combination of hardware and software; forming characteristic curve by recording the students learning process in order to promote personalized learning; making learning fun. In addition, sharing schedule of online courses helps students understand the course arrangement and have more opportunities to meet with students in the class. Big data, artificial intelligence technology, augmented reality technology, virtual reality technology and online course mode are further iterating the form of 
online education, continuously promoting the in-depth development of online education platform, and making it more efficient, intelligent and personalized. For instance,

1) the big data + education: the learning process of every student will be recorded, which is big data visualization through professional cloud computing technology. Establishing a scientific analysis model and results of the analysis help to study the dynamic and real-time record, personalized education plan, development trend of online education.

2) artificial intelligence + education: the evolution from digital campus to the intelligent campus can improve teaching environment, explore new teaching model based on artificial intelligence, reconstruct the teaching process, teaching monitoring and artificial intelligence diagnosis process, analysis of learning and academic level, establish multi-dimensional intelligent evaluation.

3) AR/VR+ education: the combination of augmented reality and 3D animation interactive technology can achieve image synthesis. Teaching through vivid models, interesting and comprehensive structural concepts and details can reduce the difficulty of students' understanding complex abstract problems so as to make learning more intuitive and interesting.

\section{Conclusion}

Online education is too "simple" if educators just mechanically move lectures from offline to online, and move them from the platform to the screen. Teachers should explore that how to innovate their thinking and how to apply these technologies effectively to improve teaching effect through the distance education. In addition, technology companies and operators also need to be more proactive in embedding the technologies into the education industry, and work with educators to expand new forms of education. Education will go beyond the existing educational scope and become an important carrier of national culture and soft power output.

\section{References}

1. Holmberg, B. 1983. "Guided Didactic Conversation in Distance Education". In Distance education: International Perspectives, Edited by: Sewart, D. Beckenham: Croom Helm.

2. Liu tao. Zheng Haihao. Reconstruction of Higher Online Education Communication System in the Internet Era: Based on the Theory of Indirect Network Effect [J]. Modern Distance Education Research, 2016 (4): 42-48.

3. Zhong Zhixian. Distance Education: Present Situation, Challenge and Development-An Interview with Professor Michael G. Moore. China Educational Technology[J].2014

4. "The American Journal of Distance Education" http://www.ajde.com. 